Editorial

\title{
The Analysis of Research Hotspots in the Field of Urban Quality
}

\author{
Agnieszka Bieda ${ }^{1, * \mathbb{D}}$ and Agnieszka Telega ${ }^{2}$ \\ 1 Department of Photogrammetry, Remote Sensing of Environment and Spatial Engineering, Faculty of Mining \\ Surveying and Environmental Engineering, AGH University of Science and Technology, \\ 30-059 Kraków, Poland \\ 2 Department of Real Estate and Investment Economics, Cracow University of Economics, \\ 31-510 Kraków, Poland; agnieszka.telega@uek.krakow.pl \\ * Correspondence: agnieszka.bieda@agh.edu.pl; Tel.: +48-12-617-3430
}

Citation: Bieda, A.; Telega, A. The Analysis of Research Hotspots in the Field of Urban Quality. Sustainability 2021, 13, 9582. https://doi.org/ $10.3390 /$ su13179582

Received: 19 August 2021

Accepted: 23 August 2021

Published: 25 August 2021

Publisher's Note: MDPI stays neutral with regard to jurisdictional claims in published maps and institutional affiliations.

Copyright: (c) 2021 by the authors. Licensee MDPI, Basel, Switzerland. This article is an open access article distributed under the terms and conditions of the Creative Commons Attribution (CC BY) license (https:// creativecommons.org/licenses/by/ $4.0 /)$.

\section{Introduction}

Urban areas are subject to continuous spatial and structural changes. Obviously, for their inhabitants, the most important issue is that these changes do not harm the space they live in. For this reason, it is an increasingly frequent case that the literature on urban studies includes descriptions of the research focused on the actual state of the elements of urban environment and the quality of urban areas.

Due to the different degree of urban development, it is very difficult to indicate the best way to create a city with high spatial quality or to strive for sustainable development. It is easy to agree that, despite the complexity of the quality of urban space definition, it is possible to outline the areas that influence this quality, including: transportation, land use, environmental protection, social equity, green building, safety, accessibility and spatial order $[1,2]$.

When paraphrasing the definition that the American Society for Quality (ASQ) placed on its website [3], the quality of urban areas includes some characteristics that affect their ability to meet the identified or presumed needs of their users. Moreover, this space should be free from any deficiencies in equipment and infrastructure. Thus, there are at least two threads (of space as a whole and its individual components) that can be the subject of a variety of research: (i) technological research leading to the definition of the methodology for measuring the quality of urban space; (ii) social research checking the influence of the quality of urban space on the quality of life of its inhabitants; (iii) economic research related to costs caused by insufficient quality of urban space.

An analysis of research hotspots was performed in order to check how the authors of the publications on urban quality included in the Special Issue entitled "The quality of urban areas: new measuring tools and methods, impact on quality of life and costs of bad design" fit into the worldwide research. This is a simple and effective method that helps in identifying topics that are particularly frequently discussed [4].

\section{Materials and Methods}

The authors decided to base their conclusions on the analysis performed with the use of the VOSviewer programme [5] which is quite common in similar studies [6-9]. The data necessary for its performance was taken from the Web of Science Core Collection [10]. This specific database was chosen because: (i) it has an excellent reputation in the scientific community in terms of indexing high-quality peer-reviewed publications; (ii) it provides detailed information that enables accurate results to be obtained with bibliometric analysis software; and (iii) it indexes a sufficient number of publications on the broadly understood quality of urban areas to determine general trends in global research on this subject.

The data collection was through the use of the Web of Science platform. The core words that authors searched for in publications and used as a query were: quality, urban and area. 
When creating the query, it was taken into account that the word area could appear in the plural form areas, and that these words could have been written in various configurations (quality of urban area, quality of urban areas, urban quality, urban area quality and urban areas quality). Moreover, it was found that it did not matter whether they were used in the title, abstract, as keywords, in the name of the source, or in some other field describing the publication. In the end, the query looked like this: ((( $A L L=($ "quality of urban areas" $))$ OR $A L L=$ ("quality of urban area")) OR $A L L=($ "urban quality")) OR $A L L=($ "urban area quality")) OR $A L L=$ ("urban areas quality"). The search was conducted on 30 June 2021.

The database thus generated was reduced to publications as articles, proceeding papers and book chapters. Furthermore, it required additional manual elimination of the thematically unrelated works and finally 490 publications remained. These were subjected to a simple quantitative analysis and the search results were exported to a text file. After importing the data to VOSviewer, a graphic analysis of links between the keywords describing these publications was performed. The programme analysed the keywords used by the authors to describe the publications and extracted additional keywords for the analysis from the titles of the publications and abstracts. Then, the map of knowledge on the quality of urban areas was created, which looked like a network. The analysed keywords were located at the nodal points of this network, while the lines forming it indicated the overall presence of linked keywords in the analysed documents. The size of the nodal point symbol depended on the frequency of occurrence of a given keyword and on the number of links to other analysed entries.

\section{Results and Discussion}

\subsection{Quantitative Analysis}

The first two articles on urban quality indexed in the Web of Science date back to 1976. They were published in the French magazine "L'Architecture d'Aujourd'hui" and concern recovering urban quality [11] and return to urban quality [12]. Until 2000, publications in this field were searched rather sporadically (from zero to two per year). After this year, an upward trend was observed. In 2007, the annual number of publications for the first time exceeded 10. The maximum annual number of publications so far was 58 in 2019.

Most publications were written in English (413), but there is also a large group of papers written in Spanish (29) and Italian (22). Other languages account for about $5 \%$ of all the searches.

The authors or co-authors of 112 publications are affiliated in Italy. This is almost $23 \%$ of all the works. Another group consists of the authors from the United States, who published just over $10 \%$ of the publications found. Interestingly, these two nations have not published jointly any of the Web of Science papers on urban quality so far.

The analysed works were published in 382 different sources. Most publications come from the Italian journal "TeMA-Journal of Land Use Mobility and Environment" (18). It is an interesting fact that although only nine papers were published in the "Landscape and Urban Planning" magazine, the first five most cited publications came from it. The authors of these research papers are affiliated in the Netherlands [13], Belgium [14], the United States [15,16] and Germany [17]. Four publications deal with different aspects of research related to green spaces. However, the most frequently cited one contains the results of literature research carried out in order to create a multidisciplinary conceptual framework for environmental quality and quality of life for the development of, e.g., urban areas.

As far as the quality of urban areas is concerned, the Americans are the most frequently cited (1223 citations). Authors from Italy (653) and the Netherlands (651) follow. It is worth adding that the Dutch placed third in this ranking, having published 27 works and took fifth place in the list of publications on the quality of urban areas indexed in the Web of Science.

It should also be mentioned that 145 of the analysed studies (almost 30\%) were assigned to the urban studies category. Other represented research fields included envi- 
ronmental studies (75), environmental sciences (59), architecture (56) and regional urban planning (52).

\subsection{Keywords}

The authors of the analysed publications described them using 1436 different keywords. Taking into account the additional words that VOSviewer had identified out of the remaining metadata describing the documents, the number of analysed keywords increased to 1991. However, not all of them were used to determine mutual links.

The selection was started by extracting only those words that occurred at least seven times. Then, in order to make graphic analyses more readable, it was decided to exclude the expressions used in the Web of Science search engine, words describing the research area, as well as those referring to quality of life and quality in general. They included: areas (8), city (36), cities (39), of-life (9), place (9), quality (10), quality of life (42), quality-of-life (12), urban (18), urban quality (43) and urban quality of life (45). As a result, 44 words remained, and the links between them were checked by determining how often the pairs of words occurred in the data describing the publications in total. As a result of the analysis, a network of keywords was created that took into account both the number of occurrences of individual words and the links between them. It is illustrated in Figure 1.

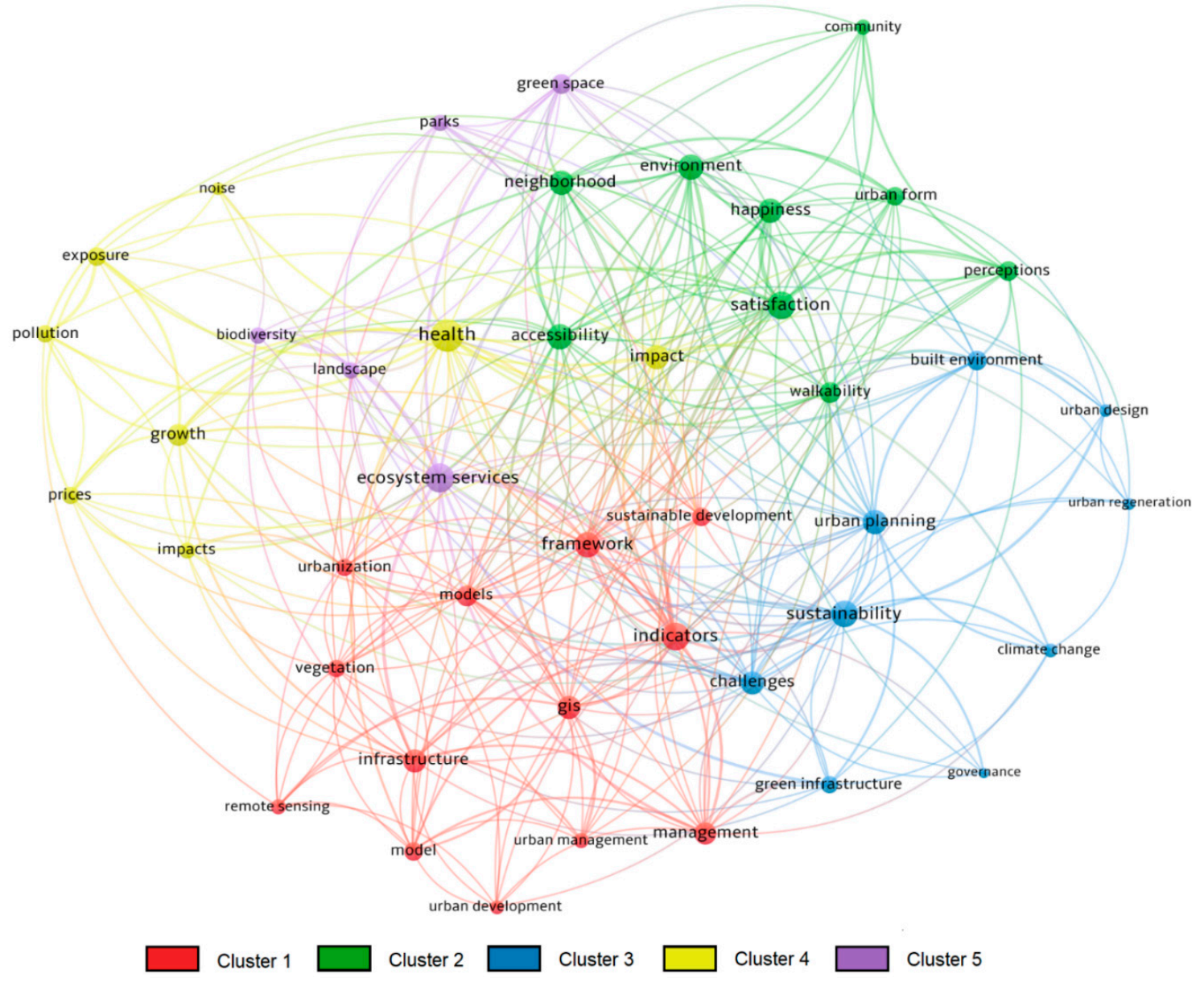

Figure 1. Keyword network.

The analysed words were divided into five thematic clusters, which are marked with colours in Figure 1. Using such a keyword network, it is easy to identify the issues on the quality of public space that are most often discussed in the literature: cluster 1-model(s), indicators and framework of the quality of urban areas, which are analysed primarily with the use of GIS tools for the management and development of these areas; cluster 2-perceptions 
of the quality of urban areas through the analysis of satisfaction and happiness with accessibility and neighbourhood among residents; cluster 3-ways to improve the quality of urban areas, such as urban planning and urban regeneration for sustainability of these areas; cluster 4-factors influencing health; cluster 5-ecosystem services available to residents of urban areas, such as green space, landscape or parks.

In order to document the thematic division of the literature on the quality of urban areas, each cluster was assigned publications selected using the keywords that were the most important for this cluster. Thus, for cluster 1, publications were found describing analyses integrating various data (including remote sensing) in order to measure the quality of urban space [18] and the quality of life in urban space [19] using GIS tools. The most representative publications for cluster 2 are publications on surveys, which help to understand the relationship between the attributes of the urban environment and the subjective sense of the quality of urban space $[20,21]$. The publications whose keywords come from cluster 3 most commonly describe procedures of urban planning and revitalisation $[22,23]$. Works matching the keywords from cluster 4 focus on health, and in fact mainly on air quality, which can have a large impact on overall health [24]. The publications related to cluster 5 mainly concern aesthetic aspects resulting from the introduction of greenery to cities [25] and the influence of this greenery on the well-being of their inhabitants [26].

As is visible in the keyword network, when searching for publications matching a specific cluster, it was noticed that there were many research works that were described with keywords from several clusters. For example, there was a publication on preferences as to the usefulness and quality of green space [16], or GIS tools facilitating social participation in urban regeneration [27].

\section{Conclusions}

Despite the visible research hotspots, the created keyword network is very consistent. The points that make it up are evenly distributed in space and their size is similar. This is due to the fact that in the collection of the analysed papers it is very difficult to find any that could be assigned to one network cluster only. This undoubtedly proves the high complexity of the research problem of the quality of urban areas and the multidisciplinarity of this issue.

With reference to preliminary predictions, it should be noted that clusters cover both technological and social research. The lack of a clear indication of economic research does not mean, however, that these aspects are completely ignored by the authors dealing with the quality of urban areas. In the keyword network, the keyword prices can be found, which has been assigned to cluster 4 . It occurs nine times in the analysed publications and is linked to 11 other keywords. These publications mainly concern the value of real estate as an indicator of urban quality [28] or the influence of the factors affecting this quality of urban space on the value of individual real properties [29,30].

It should also be noted that the method of searching for publications for the analysis brought very limited results. This resulted in a situation where the review lacked a broader perspective. For this reason, the analysed documents did not include research papers published in the Special Issue, which this editorial paper is summary of. Nevertheless, there is a clear relationship between these research papers and the topics discussed in the analysed documents. Noise, which was a springboard to the performed research described in [31] and which is part of cluster 4, occurred seven times in the analysed documents and is linked to seven other keywords. Green space, which is the subject of the analysis in [32], occurred in the metadata nine times, has 16 links and was assigned to cluster 5. Walkability, the new measurement method of which is presented in [33], was the subject of research described in eight publications from the analysed set, is linked to 15 other words and is part of cluster 2. Article [34] uses GIS tools (cluster 1, 17 links, 21 occurrences) to analyse the quality of life, which is related to the quality of urban space to a great extent. The indicators used in this research (cluster 1, 20 links, 20 occurrences) were, e.g., the 
previously mentioned noise and green space. Urban design, which occurs in 12 documents and is linked to seven other keywords, and which can be found in cluster 3 , was in turn a contribution to the analyses described in [35]. It is worth to notice, that the articles accepted for the Special Issue are representative of each cluster, that is, a group of issues related to the quality of urban space.

Author Contributions: Conceptualization, A.B. and A.T.; methodology, A.B.; software, A.B.; validation, A.B. and A.T.; formal analysis, A.B.; investigation, A.B.; resources, A.B.; data curation, A.B.; writing-original draft preparation, A.B. and A.T.; writing—review and editing, A.T.; visualization, A.B.; supervision, A.B.; project administration, A.B.; funding acquisition, A.B. and A.T. All authors have read and agreed to the published version of the manuscript.

Funding: This work was partly prepared within the scope of the research funds the AGH University of Science and Technology in Kraków and the Cracow University of Economics.

Institutional Review Board Statement: Not applicable.

Informed Consent Statement: Not applicable.

Data Availability Statement: This study analysed data collected from a Web of Science database search [https://www.webofscience.com/wos/woscc/basic-search], which was conducted on 30 June 2021.

Acknowledgments: The guest editors would like to thank all who contributed directly and indirectly to the successful development of this Special Issue. Many thanks are due to all the scholars and authors who submitted their manuscripts and were willing to publish their research activities in this Special issue. Particular mention and sincere thanks to the reviewers who agreed to review the articles and provide feedback to improve the quality of the manuscripts. Credits should also be given to all the staff of the Sustainability Editorial Office for their contribution and support in the publication process of this issue.

Conflicts of Interest: The authors declare no conflict of interest.

\section{References}

1. Hiremath, R.B.; Balachandra, P.; Kumar, P.; Bansode, S.S.; Murali, J. Indicator-based urban sustainability-A review. Energy Sustain. Dev. 2013, 17, 555-563. [CrossRef]

2. Ewing, R.; Clemente, O. Measuring Urban Design: Metrics for Liveable Places; Island Press: Washington, DC, USA, 2013.

3. Quality Glossary_Letter “Q” of American Society for Quality. Available online: https://asq.org/quality-resources/qualityglossary / q (accessed on 30 June 2021).

4. $\quad$ Barthel, M.; Fava, J.A.; Harnanan, C.A.; Strothmann, P.; Khan, S.; Miller, S. Hotspots analysis: Providing the focus for action. In Life Cycle Management. LCA Compendium -The Complete World of Life Cycle Assessment; Sonnemann, G., Margni, M., Eds.; Springer: Dordrecht, The Netherlands, 2015; pp. 149-167. [CrossRef]

5. Van Eck, N.J.; Waltman, L. Software survey: VOSviewer, a computer program for bibliometric mapping. Scientometrics 2010, 84, 523-538. [CrossRef]

6. Peponi, A.; Morgado, P. Smart and regenerative urban growth: A literature network analysis. Int. J. Environ. Res. Public Health 2020, 17, 2463. [CrossRef] [PubMed]

7. Sharifi, A. Urban sustainability assessment: An overview and bibliometric analysis. Ecol. Indic. 2020, 121, 107102. [CrossRef]

8. Li, T.; Cui, L.; Xu, Z.; Hu, R.; Joshi, P.K.; Song, X.; Tang, L.; Xia, A.; Wang, Y.; Guo, D.; et al. Quantitative analysis of the research trends and areas in grassland remote sensing: A scientometrics analysis of web of science from 1980 to 2020. Remote Sens. 2021, 13, 1279. [CrossRef]

9. Ying, J.; Zhang, X.; Zhang, Y.; Bilan, S. Green infrastructure: Systematic literature review. Econ. Res. 2021, 1-24. [CrossRef]

10. Web of Science Core Collection. Available online: https://www.webofscience.com/wos/woscc/basic-search (accessed on 30 June 2021).

11. Benamo, G.; de Portzamparc, C. Recovering urban quality. L'Architecture D'aujourd'hui 1976, 184, 86-92.

12. Gangneux, M.C.; Pereira, J.N.; Paciencia, J. The return to urban quality. L'Architecture D'aujourd'hui 1976, 185, 27-29.

13. Van Kamp, I.; Leidelmeijer, K.; Marsman, G.; De Hollander, A. Urban environmental quality and human well-being: Towards a conceptual framework and demarcation of concepts; a literature study. Landsc. Urban Plan. 2003, 65, 5-18. [CrossRef]

14. Van Herzele, A.; Wiedemann, T. A monitoring tool for the provision of accessible and attractive urban green spaces. Landsc. Urban Plan. 2003, 63, 109-126. [CrossRef]

15. De Sousa, C.A. Turning brownfields into green space in the City of Toronto. Landsc. Urban Plan. 2003, 62, 181-198. [CrossRef] 
16. Wendel, H.E.W.; Zarger, R.K.; Mihelcic, J.R. Accessibility and usability: Green space preferences, perceptions, and barriers in a rapidly urbanizing city in Latin America. Landsc. Urban Plan. 2012, 107, 272-282. [CrossRef]

17. Kabisch, N.; Haase, D. Green spaces of European cities revisited for 1990-2006. Landsc. Urban Plan. 2013, 110, 113-122. [CrossRef]

18. Apparicio, P.; Séguin, A.M.; Naud, D. The quality of the urban environment around public housing buildings in Montréal: An objective approach based on GIS and multivariate statistical analysis. Soc. Indic. Res. 2008, 86, 355-380. [CrossRef]

19. Li, G.; Weng, Q. Measuring the quality of life in city of Indianapolis by integration of remote sensing and census data. Int. J. Remote Sens. 2007, 28, 249-267. [CrossRef]

20. Oktay, D.; Marans, R.W. Overall quality of urban life and neighborhood satisfaction: A household survey in the walled city of Famagusta. Open House Int. 2010, 35, 27-36. [CrossRef]

21. Von Breymann Miranda, H. Indicadores de percepción de calidad del entorno residencial: Una herramienta para la planificación urbana. Caso de estudio del cantón de Flores, Costa Rica. Rev. INVI 2019, 34, 101-132. [CrossRef]

22. Bruns-Berentelg, J.; Noring, L.; Grydehøj, A. Developing urban growth and urban quality: Entrepreneurial governance and urban redevelopment projects in Copenhagen and Hamburg. Urban Stud. 2020. [CrossRef]

23. Ricci, L. Rome: A strategy of urban and metropolitan re-balance. CyTET-Ciudad Y Territ. Estud. Territ. 2017, 49, 533-534.

24. Riondato, E.; Pilla, F.; Basu, A.S.; Basu, B. Investigating the effect of trees on urban quality in Dublin by combining air monitoring with i-Tree Eco model. Sustain. Cities Soc. 2020, 61, 102356. [CrossRef]

25. Lindemann-Matthies, P.; Brieger, H. Does urban gardening increase aesthetic quality of urban areas? A case study from Germany. Urban For. Urban Green. 2016, 17, 33-41. [CrossRef]

26. Larson, L.R.; Jennings, V.; Cloutier, S.A. Public parks and wellbeing in urban areas of the United States. PLoS ONE 2016, 11, e0153211. [CrossRef] [PubMed]

27. Omidipoor, M.; Jelokhani-Niaraki, M.; Moeinmehr, A.; Sadeghi-Niaraki, A.; Choi, S.M. A GIS-based decision support system for facilitating participatory urban renewal process. Land Use Policy 2019, 88, 104150. [CrossRef]

28. D'Acci, L. Monetary, subjective and quantitative approaches to assess urban quality of life and pleasantness in cities (hedonic price, willingness-to-pay, positional value, life satisfaction, isobenefit lines). Soc. Indic. Res. 2014, 115, 531-559. [CrossRef]

29. Morano, P.; Tajani, F.; Di Liddo, F.; Darò, M. Economic evaluation of the indoor environmental quality of buildings: The noise pollution effects on housing prices in the city of Bari (Italy). Buildings 2021, 11, 213. [CrossRef]

30. Del Giudice, V.; Torrieri, F.; De Paola, P. Property value, urban quality and maintenance condition: A hedonic analysis in the city of Naples, Italy. Adv. Eng. Forum 2014, 11, 560-565. [CrossRef]

31. Bełej, M.; Cellmer, R.; Głuszak, M. The impact of airport proximity on single-family house prices-Evidence from Poland. Sustainability 2020, 12, 7928. [CrossRef]

32. Kwartnik-Pruc, A.; Trembecka, A. Public green space policy implementation: A case study of Krakow, Poland. Sustainability 2021, 13, 538. [CrossRef]

33. Telega, A.; Telega, I.; Bieda, A. Measuring walkability with GIS-Methods overview and new approach proposal. Sustainability 2021, 13, 1883. [CrossRef]

34. Vakilipour, S.; Sadeghi-Niaraki, A.; Ghodousi, M.; Choi, S.-M. Comparison between multi-criteria decision-making methods and evaluating the quality of life at different spatial levels. Sustainability 2021, 13, 4067. [CrossRef]

35. Aouad, D.; Kaloustian, N. Sustainable Beirut City planning post august 2020 Port of Beirut Blast: Case study of Karantina in Medawar district. Sustainability 2021, 13, 6442. [CrossRef] 